\title{
Effect of exogenous oxytocin on the leakage of lactose from the mammary gland and on suckling-induced plasma prolactin in the lactating rat
}

\author{
Y. Yamamuro* and N. Sensui \\ Department of Animal Science, College of Agriculture and Veterinary Medicine, Nihon University, \\ Fujisawa, Kanagawa 252, Japan
}

\begin{abstract}
The leakage of lactose from the mammary gland into plasma and the increase in the suckling-induced concentration of prolactin in the plasma of oxytocin-injected lactating rats suckling different numbers of pups were investigated. Rats nursing eight pups were isolated from their litter for $6 \mathrm{~h}$ and injected i.v. with either $\mathrm{I}$ iu oxytocin or saline and allowed to resuckle either two, eight or 12 pups for $1 \mathrm{~h}$. The concentration of lactose in plasma increased significantly in rats injected with oxytocin and allowed to resuckle two or eight pups; however, there was no difference in rats allowed to resuckle 12 pups. When compared within oxytocin-injected groups, the concentration of lactose was significantly lower in rats allowed to resuckle eight or 12 pups than in rats allowed to resuckle only two pups. Plasma prolactin concentrations increased during the suckling period in mothers suckling either eight or 12 pups, and oxytocin diminished the increase in prolactin concentration in both groups. In rats suckling two pups, prolactin release was not observed. The second objective of this study was to determine the relationship between the leakage of lactose from the mammary gland by oxytocin injection and suckling. Mothers that had the three left nipples of their mammary glands occluded were isolated from their litter of eight pups for $6 \mathrm{~h}$ and were allowed to resuckle with eight pups for $1 \mathrm{~h}$. At the start of resuckling, 0.01, 0.1 or 1 iu oxytocin was injected i.v. The amount of lactose in the occluded mammary glands was not altered by the administration of either 0.01 or 0.1 iu of oxytocin or by saline, whereas $I$ iu oxytocin significantly decreased it. The amount of lactose in the non-occluded side decreased with oxytocin in a dose-dependent manner. The present study indicates that the transfer of lactose from milk to plasma by exogenous oxytocin diminishes with milk removal, or that unknown mechanism(s) are induced by suckling. Prolactin release during suckling increased with increasing litter size and oxytocin administration attenuated the increase.
\end{abstract}

\section{Introduction}

During lactation, the suckling stimulus causes the release of prolactin from the anterior pituitary and oxytocin from the posterior pituitary. Oxytocin evokes milk ejection and prolactin stimulates the synthesis of milk components, such as casein and lactose, by the mammary gland. The actions of oxytocin and prolactin maintain lactation and the quantity of milk produced is determined by the suckling intensity of the number of pups attached to the nipples of mothers (Russell, 1980; Grigor et al, 1984).

The concentration of lactose in plasma increases when the interval between milking is extended (Wheelock and Rook, 1966), at parturition and after weaning (Kuhn and Linzell, 1970;

*Present address: Department of Physiology, Saitama Medical School, 38 Morohongo, Moroyama, Iruma-gun, Saitama 350-04, Japan. Received 8 April 1994
Hartmann et al., 1984; Matte et al., 1989). The lactose content of the mammary gland decreases rapidly and the lactose concentration of the plasma increases coincidently in response to oxytocin administration to lactating rats that had been isolated from their litter for $6 \mathrm{~h}$ (Yamamuro et al., 1993). The administration of oxytocin also decreases the amount of lactose in milk in lactating cows (Wheelock et al., 1965; Lane et al., 1970; Graf et al., 1973). It has been suggested that lactose leaks from milk in the mammary gland into the plasma, and that the mechanism by which this occurs depends on the opening of tight junctions between mammary epithelial cells in response to the accumulation of milk in the mammary gland during long intervals between milking, around parturition and after weaning (Pitelka ef al., 1973; Linzell and Peaker, 1974; Morgan and Wooding, 1982). A recent study has shown that when tight junctions in mammary glands are disrupted during extended milking intervals in goats, the plasma lactose concentration increases (Stelwagen et al., 1994). 
The objective of the present study was to examine whether oxytocin administration induces the disruption of tight junctions in mammary glands as an index of the leakage of lactose from milk to plasma during suckling. The effect of oxytocin in rats suckling different numbers of pups on the suckling-induced release of prolactin and the milk ejection reflex in lactating rats were also examined.

\section{Materials and Methods}

\section{Animals and treatments}

Primiparous lactating rats of the Wistar strain were housed in individual cages at $22 \pm 1^{\circ} \mathrm{C}$ under a photoperiod of $14 \mathrm{~h}$ light: $10 \mathrm{~h}$ dark (lights on at 06:00 h). They were allowed free access to food and water. The litter was adjusted to eight pups on day 1 of lactation (the day after parturition). A permanent intra-atrial catheter was inserted into the mother on day 5 of lactation. Synthetic lyophilized oxytocin (Pitocin: Sigma Chemical Co., St Louis, MO) dissolved in saline was used in this study.

Experiment 1. At $09: 00 \mathrm{~h}$ on day 12 of lactation, mothers $(n=45)$ were isolated from their litters. After isolation for $6 \mathrm{~h}$, mothers were allowed to resuckle for $I \mathrm{~h}$; the size of the litter was adjusted to either two, eight or 12 pups. Oxytocin ( 1 iu in $0.1 \mathrm{ml}$ saline) was inserted into the mothers through the catheter at the beginning of the resuckling period. Saline $(0.1 \mathrm{ml})$ was infused via the catheter into the control rats. The difference in body mass of the litter before and after the $1 \mathrm{~h}$ suckling was used as an index of the amount of milk ejected from the mothers. Blood samples $(300 \mu \mathrm{l})$ were taken through the catheter just before oxytocin injection $(0 \mathrm{~min})$, and 15, 30 and $45 \mathrm{~min}$ after injection of oxytocin to estimate the concentration of suckling-induced biologically active prolactin; an equal volume of saline was injected into the mothers after each blood sampling. Blood was collected by cardiac puncture under light ether anaesthesia at the end of the suckling period to measure the concentration of lactose in plasma.

Experiment 2. At $09: 00 \mathrm{~h}$ on day 12 of lactation, mothers $(n=24)$ were isolated from their litters (eight pups), and the three most left-hand nipples of abdominal inguinal mammary glands of the mother were occluded by surgical adhesive agent. After being isolated from their pups for $6 \mathrm{~h}$, mothers were allowed to resuckle with eight pups for $1 \mathrm{~h}$. At the start of resuckling, $0.01,0.1,1$ iu oxytocin (in $0.1 \mathrm{ml}$ saline) or $0.1 \mathrm{ml}$ saline was administered through the catheter. After the $\mathrm{I} \mathrm{h}$ suckling period, blood was taken by cardiac puncture under light ether anaesthesia and the mothers were killed by decapitation.

\section{Lactose in plasma and mammary glands}

Blood taken from the mother by cardiac puncture was drawn into the heparinized tube, centrifuged at $1000 \mathrm{~g}$ for $20 \mathrm{~min}$ at $4^{\circ} \mathrm{C}$, and the plasma obtained was stored at $-30^{\circ} \mathrm{C}$ until assayed for lactose. At the autopsy in Expt 2, occluded and unoccluded abdominal inguinal mammary glands were removed and weighed separately. The lactose in plasma and in mammary glands was determined by an enzymatic method (Harigaya et al., 1978).

\section{Concentration of biologically active prolactin in plasma}

Blood $(300 \mu \mathrm{l})$ drawn into a tube containing $300 \mu \mathrm{l}$ heparinized (100 U heparin $\mathrm{ml}^{-1}$ ) $0.01 \mathrm{~mol} \mathrm{PBS} \mathrm{l}^{-1}(\mathrm{pH} \mathrm{7.4)}$ was centrifuged at $1000 \mathrm{~g}$ for $20 \mathrm{~min}$ at $4^{\circ} \mathrm{C}$. The plasma was stored at $-30^{\circ} \mathrm{C}$ and the biologically active prolactin concentration was assayed using the $\mathrm{Nb2}$ rat lymphoma cell bioassay (Lawson et al., 1982). In the assay, NIADDK rPRL-B-4 was used as the standard and the amount of plasma sample diluted with PBS was usually $50 \mu \mathrm{l}$. Each sample was assayed in duplicate and the mean was used as the representative value of the sample.

\section{Statistical analyses}

Statistical significance was based on the two-way analysis of variance and Duncan's new multiple range test. Student's $t$ test was used to test for statistical significance between groups with the same number of pups. Values that were different at a level of $P<0.05$ were considered significant.

\section{Results}

\section{Experiment 1}

The gain in body mass of individual pups in saline-injected rats suckling two pups during the $1 \mathrm{~h}$ suckling period was markedly lower than that of eight pups $(P<0.01)$ and 12 pups $(P<0.001$; Fig. 1). A comparison between the saline-injected control and the oxytocin-injected groups suckling the same number of pups indicated that the litters of oxytocin-injected rats suckling two or eight pups were heavier than the equivalent control groups. In addition, the gain in body mass per pup in the group suckling two pups was significantly greater than those in the other two groups $(P<0.01$ for eight pups and $P<0.001$ for 12 pups). Also, the pups from the rats suckling eight pups had a greater mass gain than did the pups from the group suckling 12 pups. Thus, an inverse relationship was seen between the gain in body mass of a pup during the suckling period and the number of pups per litter in oxytocin-injected groups $(r=-0.859 ; P<0.01)$.

The increase in the litter size suckled resulted in a significant decrease in the concentration of plasma lactose in both oxytocin- and saline-injected groups (Fig. 2). When the plasma lactose concentration of oxytocin-injected groups was compared between groups of rats that suckled the same number of pups, the concentration was significantly higher $(P<0.001$ for two pups and $P<0.05$ for eight pups) than that of the saline-injected controls. Particularly, the concentration of lactose in rats suckling two pups increased by a factor of approximately 10 in response to oxytocin administration. The 
(a)

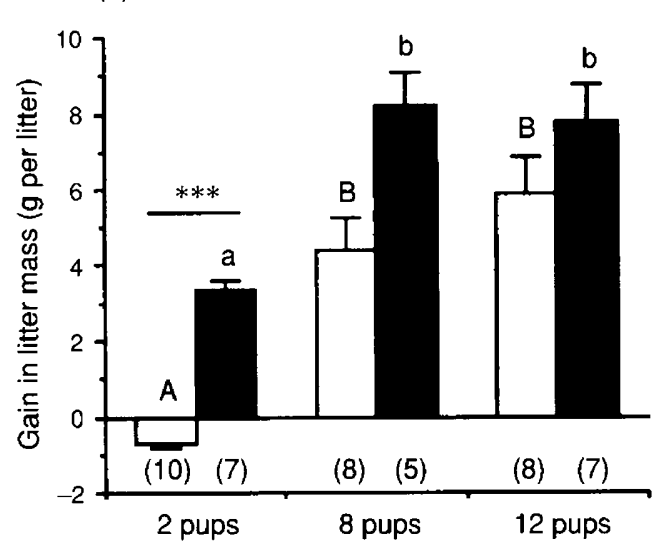

(b) $* * *$

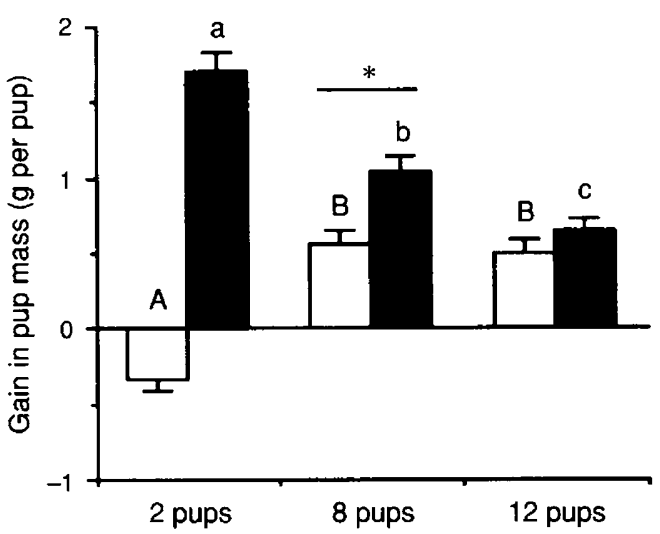

Fig. 1. Effects of exogenous oxytocin ( 1 iu i.v.) to lactating rats suckled with different litter sizes on the gain in the mass of (a) litter and (b) individual pups (mean \pm SEM) at the end of a $1 \mathrm{~h}$ suckling period after $6 \mathrm{~h}$ separation from their mother. Different capital letters (saline, $\square$ ) and small letters (oxytocin, $\square$ ) indicate a significant difference between the values $(P<0.05) . * * *$ Values are significantly different between saline- and oxytocin-injected rats suckling the same number of pups $(P<0.05$ and 0.001 , respectively). Numbers of rats tested are in parentheses.

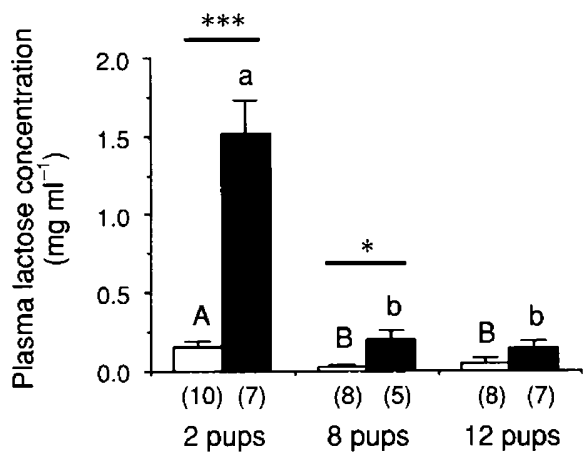

Fig. 2. Effects of oxytocin ( 1 iu i.v.) administered to lactating rats suckled with different litter sizes on the concentration of lactose in the plasma of the mothers (mean \pm SEM) after a $1 \mathrm{~h}$ suckling period foliowing $6 \mathrm{~h}$ isolation from their litter. Different capital letters (saline, $\square$ ) and small letters (oxytocin, $\mathbf{\square}$ ) indicate a significant difference between the values $(P<0.05) .{ }^{*}, * * *$ Values are significantly different between saline- and oxytocin-injected rats suckling the same number of pups $(P<0.05$ and 0.001 , respectively). Numbers of rats tested are in parentheses.

plasma lactose concentration in the group suckling 12 pups also tended to be higher in oxytocin-injected rats, but this increase was not statistically significant.

In the rats suckling two pups, the concentration of sucklinginduced prolactin in plasma was not higher in either oxytocininjected rats or saline-injected control rats (Fig. 3a). In the rats suckling eight pups, suckling gradually increased the concentration of plasma prolactin in both groups over time, but the increase was not significantly different in the oxytocin-injected group (Fig. 3b). In the rats suckling 12 pups the concentration of prolactin in plasma continued to increase following the initiation of suckling in both saline-injected and oxytocininjected animals (Fig. 3c). However, in oxytocin-injected rats suckling eight or 12 pups, the increase in concentration of prolactin in plasma was lower than that in the respective saline-injected rats. The prolactin concentration in rats suckled by 12 pups tended to be higher than in those suckling eight pups at all times measured.

\section{Experiment 2}

The mass of the mammary gland of the occluded side was not altered by any dosage of oxytocin (Fig. 4a). The difference between the mass of occluded and suckled mammary glands, which is considered to be equal to the amount of milk removed from the mammary glands by the litter, was greater in oxytocin-injected rats than in the control rats (data not shown). The amount of lactose in the occluded mammary glands was not significantly different among groups except for the group injected with 1 iu oxytocin (Fig. 4b). Administration of $I$ iu oxytocin markedly decreased the amount of lactose in the occluded side and was significantly different $(P<0.001)$ from the other groups. In contrast, the amount of lactose in the suckled sides decreased in response to the administration of oxytocin in a dose-dependent manner. Concentration of lactose in the plasma of the rats injected with 1 iu oxytocin was significantly higher $(P<0.05)$ than that in the control rats and in those rats injected with 0.01 and 0.1 iu oxytocin (Fig. 5).

\section{Discussion}

The study has shown that suckling diminishes the leakage of lactose from milk to plasma by oxytocin administration in the lactating rat.

Reducing the litter from eight to two pups resulted in a loss of the body mass of the litter during a $1 \mathrm{~h}$ suckling period. This result indicates that a considerable reduction in the litter size does not induce the release of endogenous oxytocin from the posterior pituitary. The amount of oxytocin released appears to depend on the number of pups attached to the nipples (Fuchs and Wagner, 1963; Mena and Grosvenor, 1968), and the 

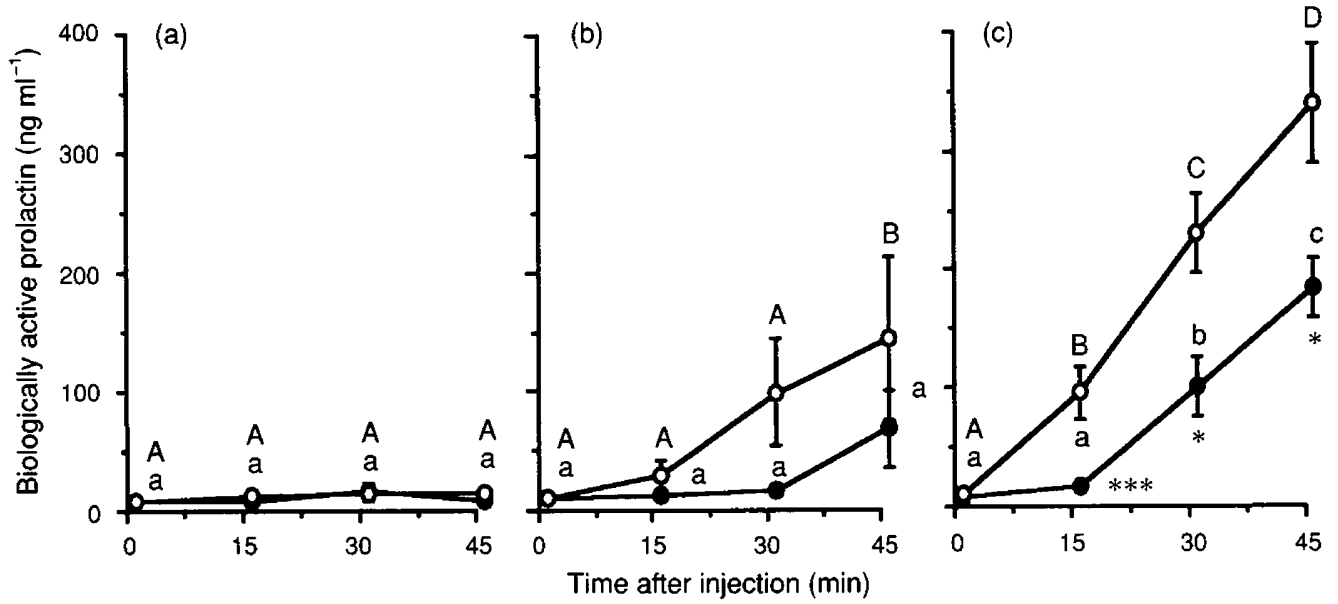

Fig. 3. The concentration of suckling-induced biologically active prolactin in the plasma of rats (mean \pm SEM) during the suckling period. Mothers were injected with oxytocin ( 1 iu i.v.) or saline and suckled by (a) two, (b) eight or (c) 12 pups. Different capital letters (saline, $O$ ) and small letters (oxytocin, 0 ) indicate a significant difference between values $(P<0.05){ }^{*}, * * *$ Values are significantly different between saline- and oxytocininjected rats suckling the same number of pups $(P<0.05$ and 0.001 , respectively).

(a)

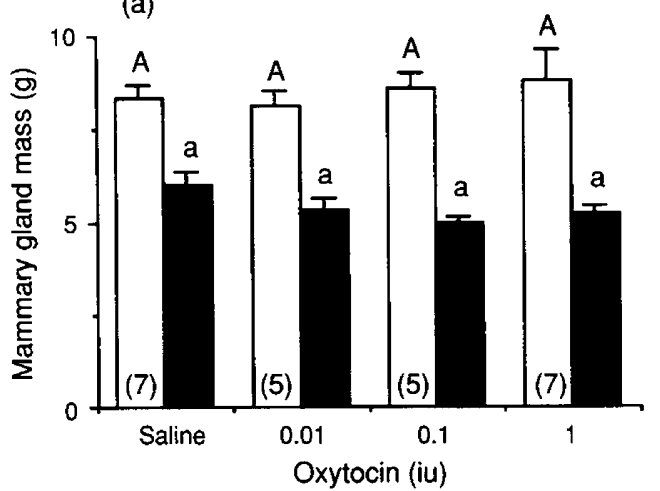

(b)

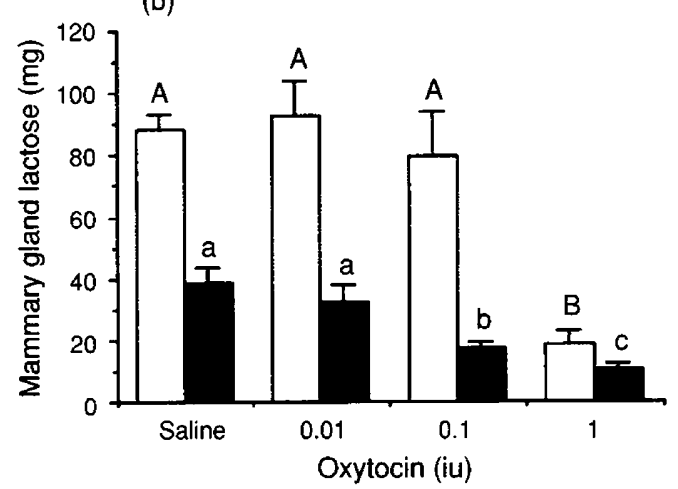

Fig. 4. (a) The mass and (b) the lactose content (mean \pm SEM) of occluded ( $\square$ ) and suckled ( $\square$ ) mammary glands in lactating rats that had been injected with various doses of oxytocin and that had suckled eight pups for $1 \mathrm{~h}$ after $6 \mathrm{~h}$ of isolation from their litter. Different capital letters (occluded) and small letters (suckled) indicate a significant difference between values $(P<0.05)$. Numbers of rats tested are in parentheses.

threshold for the suckling-induced reflex release of oxytocin is, at least in part, set by the previous suckling experience of mothers (Wakerley et al., 1978). A comparison between salineand oxytocin-injected groups suckling the same number of pups indicated that the gain in litter mass in oxytocin-injected groups was significantly greater, or tended to be greater, and is due to the removal of alveolar milk. Moreover, reducing the number of pups suckled increased the gain in bodymass of an individual pup when oxytocin was administered. This result suggests that an individual pup in the groups suckling two or eight pups suckled from more than one nipple. The litter in the group suckling two pups could obtain milk only with the aid of exogenous oxytocin.

The amount of prolactin released from the anterior pituitary during suckling depends on the intensity of the suckling stimulus (Grosvenor and Mena, 1971; Grigor et al., 1984). In the experiment reported here, the maternal biologically active plasma prolactin concentration also increased with increasing litter size, while the increase of prolactin in oxytocin-injected groups was lower than that of the controls. One possible reason for the diminution of suckling-induced prolactin release by oxytocin administration is a decrease in the suckling intensity; this seems likely since litters could obtain milk more easily in response to exogenous oxytocin administration. There are some reports that a large dose of oxytocin decreases the release of prolactin from the anterior pituitary (Kuhn and McCann, 1970; Kuhn et al., 1973). In addition, in the study reported here, the biologically active prolactin concentration in the plasma of oxytocin-injected rats suckling eight pups tended to be lower than that of the control, and in the oxytocin-injected rats suckling 12 pups the plasma prolactin concentration was significantly lower at all periods measured compared with those of the control groups. The results appear to confirm that the suckling-induced prolactin release was suppressed by exogenous oxytocin during the $1 \mathrm{~h}$ suckling period.

It has also been observed that prolactin release during a suckling period is delayed if oxytocin is injected, while fewer 


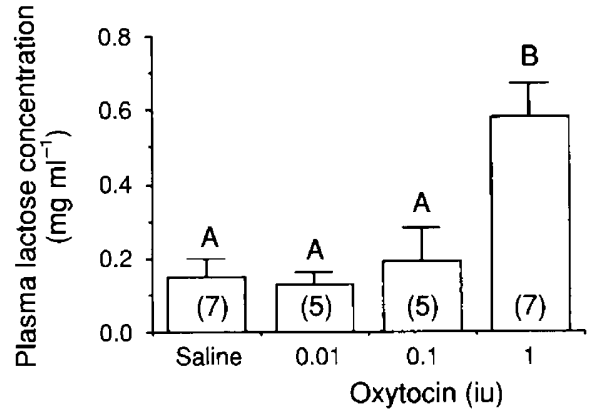

Fig. 5. The concentration of lactose in plasma (mean \pm SEM) in lactating rats that were injected with $0.01,0.1$ or 1 iu oxytocin and that suckled eight pups for $1 \mathrm{~h}$ after $6 \mathrm{~h}$ isolation from their litter. Points within a group with different letters are significantly different from each other $(P<0.05)$. Numbers of rats tested are in parentheses.

stretching reactions of litters did not occur in oxytocin-injected groups compared with those in control rats, and prolactin is normally released by the suckling stimulus after the efficacy of oxytocin administered has disappeared (Y. Yamamuro and N. Sensui, unpublished). Thus, it is possible that the decrease in suckling-induced prolactin release is a direct action of oxytocin. Recently, several researchers have reported that prolactin release is induced by oxytocin administration either in vivo or in vitro, and that the plasma concentration of suckling-induced prolactin is decreased by oxytocin antiserum (Lumpkin et al., 1983; Samson ef al., 1986). Other studies, however, have shown that an oxytocin receptor antagonist (Johnston and Negro-Vilar, 1988) and oxytocin antiserum (Nagai et al., 1983) abolishes the milk ejection reflex but does not affect concentrations of plasma prolactin. Thus, further investigation is needed to resolve whether oxytocin is a physiological regulator of prolactin.

The concentration of lactose in plasma remained low $6 \mathrm{~h}$ after removal of the litter $\left(0.072 \pm 0.032 \mathrm{mg} \mathrm{ml}^{-1}\right)$ and increased after $7 \mathrm{~h}\left(0.325 \pm 0.150 \mathrm{mg} \mathrm{ml}^{-1}\right)$. This weaning duration is the critical period in the strain of rats used in this study when lactose in the milk begins to leak into the blood. The concentration of lactose in plasma in the saline-injected mothers that were suckled during the last hour of weaning tended to be lower compared with the value after $7 \mathrm{~h}$ without $1 \mathrm{~h}$ suckling. The results of Expt 1 indicate the following. First, in rats suckling two pups, milk in the mammary gland was not removed because of the lack of a sufficient suckling stimulus, as indicated by litter mass gain. Second, in rats suckling eight or 12 pups, milk was removed from the mammary gland by the pups; therefore, the amount of lactose in the plasma was low. In oxytocin-injected groups, the plasma lactose concentration of rats suckling two pups was markedly higher than in those suckling eight or 12 pups. This result indicated that the lactose in the nonsuckled mammary gland was transferred into the plasma. The removal of milk from most of the mammary gland by the numerous pups resulted in a lower concentration of lactose in the plasma.

In Expt 2, the amount of lactose in the mammary gland in the occluded side decreases in response to the administration of oxytocin at a dose of 1 iu to $21 \%$ of the amount of lactose in control rats, while 0.01 iu and 0.1 iu oxytocin did not affect the amount of lactose. However, in a previous study (Yamamuro et al., 1993) when mothers were injected with oxytocin at graded doses $(0.01,0.1$ and $1 \mathrm{iu})$ without suckling after $6 \mathrm{~h}$ of isolation from their litter, a dose-dependent decrease in the lactose content of the mammary gland was observed $(71 \%$, $58 \%$ and $14 \%$ of that of the control, respectively). Allen (1990) also reported the same dose-dependent response to oxytocin in lactating cows. The difference between these reports and the present results indicates that suckling diminishes the transfer of lactose from mammary glands to the plasma. This suggests that unknown mechanism(s) other than the decrease in intramammary pressure by milk removal are involved, since the amount of lactose in occluded glands in rats administered 0.01 and 0.1 iu oxytocin did not decline even though milk was not removed. Oxytocin administration allows the pups to remove milk with a minimum amount of suckling stimulus, as evidenced by a lower concentration of prolactin in plasma; that is, oxytocin also diminishes the intensity of suckling by pups. In the lactating rabbit (Linzell ef al., 1975), treatment with prolactin increases the concentration of lactose in milk and $\left[\mathrm{K}^{+}\right]$in late lactation. It is possible that the permeability of mammary epithelium declines with a high concentration of prolactin in plasma. However, Hayden and Smith (1981) reported that the sensitivity of prolactin in the lactating rat to lactose synthetase activity in occluded mammary glands is lower than that in normal glands. Further investigation is needed to examine the possibility that exogenous prolactin administration alters the transfer of lactose from the mammary glands to the blood.

The authors thank R. R. Gala (Department of Physiology, Wayne State University School of Medicine, Detroit, MI) for reading the original manuscript and making invaluable suggestions, the National Hormone and Pituitary Program of the USA and S. Raiti for supplying rat prolactin.

\section{References}

Allen JC (1990) Milk synthesis and secretion rates in cows with milk composition changed by oxytocin Journal of Dairy Science 73 975-984

Fuchs AR and Wagner G (1963) Quantitative aspects of release of oxytocin by suckling in anesthetized rabbits Acta Endocrinologica 44 581-592

Graf GC, Elliott CS, Jr and Randy HA, Jr (1973) Inhibitory effect of continuous infusion of oxytocin on lactation in cows Journal of Dairy Science 56 181-183

Grigor MR, Sneyd MJ, Geursen A and Gain KR (1984) Effect of changes in litter size at mid-lactation on lactation in rats Journal of Endocrinology 101 69-73

Grosvenor CE and Mena F (1971) Effect of suckling upon the secretion and release of prolactin from the pituitary of the lactating rat Journal of Animal Science 32 (Supplement 1) 115-116

Harigaya T, Sakai S and Kohmoto K (1978) Induction of mammary prolactin receptors and lactose synthesis after ovariectomy in the pregnant mouse Endocrinologia Japonica 25 157-161

Hartmann PE, Whitely IL and Willcox DL (1984) Lactose in plasma during lactogenesis, established lactation and weaning in sows Journal of Physiology 347 453-463

Hayden TJ and Smith SV (1981) Effects of bromocriptine and occlusion of nipples on prolactin receptor and lactose synthetase activity in the mammary gland of the lactating rat Journal of Endocrinology 91 225-232

Johnston CA and Negro-Vilar A (1988) Role of oxytocin on prolactin secretion during proestrus and in different physiological or pharmacological paradigms Endocrinology 122 341-350

Kuhn ER and McCann SM (1970) An inhibitory action of large doses of oxytocin on milk yield in the lactating rat Endocrinology 87 1266-1273 
Kuhn ER, Krulich L and McCarn SM (1973) Influence of exogenously administered oxytocin on prolactin release in the lactating rat Neuroendocrinology 11 11-21

Kuhn NJ and Linzell JL (1970) Measurement of the quantity of lactose passing into mammary venous plasma and lymph in goats and a cow Journal of Dairy Research 37 203-208

Lane GT, Dill CW, Armstrong BC and Switzer LA (1970) Influence of repeated oxytocin injections on the composition of dairy cow's milk Journal of Dairy Science 53 427-429

Lawson DM, Sensui N, Haisenleder DH and Gala RR (1982) Rat lymphoma cell bioassay for prolactin: observation on its use and comparison with radioimmunoassay Life Science 31 3063-3070

Linzell JL and Peaker M (1974) Changes in colostrum composition and in the permeability of the mammary epithelium at about the time of parturition in the goat Journal of Physiology 243 129-151

Linzell JL, Peaker M and Taylor JC (1975) The effects of prolactin and oxytocin on milk secretion and on the permeability of the mammary epithelium in the rabbit Journal of Physiology 253 547-563

Lumpkin MD, Samson WK and McCann SM (1983) Hypothalamic and pituitary sites of action of oxytocin alter prolactin secretion in the rat Endocrinology 112 1711-1717

Matte JJ, Guilbault LA, Dubreuil P, Petitclerc D and Pelletier G (1989) Plasma lactose after weaning and its relationship with the lactose content of milk, post-weaning plasma oestradiol-17 $\beta$ and weaning to mating interval in sows Reproduction, Nutrition and Development 29 75 -82

Mena F and Grosvenor CE (1968) Effect of the number of pups upon the suckling-induced fall in pituitary prolactin concentration and milk-ejection in the rat Endocrinology $82623-626$
Morgan G and Wooding FBP (1982) A freeze-fracture study of tight junction structure in sheep mammary gland epithelium during pregnancy and lactation Journal of Dairy Research 49 I-11

Nagai T, Makino T, Nakayama A, Suzuki H and lizuka R (1983) Study on the role of oxytocin in lactating rats by passive immunization Asia-Oceania Journal of Obstetrics and Gynecology 9 109-115

Pitelka DR, Hamamoto ST, Duafala JG and Nemanic MK (1973) Cell contents in the mouse mammary gland. I. Normal gland in postnatal development and the secretory cycle Joumal of Cell Biology 56 797-818

Russell JA (1980) Milk yield, suckling behaviour and milk ejection in lactating rat nursing litters of different size Journal of Physiology 303 403-4I5

Samson WK, Lumpkin MD and McCann SM (1986) Evidence for a physiological role for oxytocin in the control of prolactin secretion Endocrinology 119 554-560

Stelwagen K, Davis SR, Farr VC, Prosser CG and Sherlock RA (1994) Mammary epithelial cell tight junction and mammary blood flow during an extended milking interval in goats Journal of Dairy Science 77 426-432

Wakerley JB, O'Neill DS and ter Haar MB (1978) Relationship between the suckling-induced release of oxytocin and prolactin in the urethaneanaesthetized lactating rat Journal of Endocrinology 76 493-500

Wheelock JV and Rook JFA (1966) Lactose in the blood and urine of cows journal of Dairy Research 33 37-42

Wheelock JV, Rook JAF and Dodd FH (1965) The effect of intravenous injections of oxytocin during milking and the removal of residual milk on the composition of cow's milk Journal of Dairy Research 32 255-262

Yamamuro Y, Sensui N and Mizuno H (1993) Movement of milk components between marmmary glands and plasma by exogenous oxytocin in lactating rats Journal of Reproduction and Development 39 157-161 